DOI: $\underline{10.20472 / E S .2019 .8 .1 .006}$

\title{
CONDITIONAL DEPENDENCE STRUCTURE IN THE PRECIOUS METALS FUTURES MARKET
}

\section{MAŁGORZATA JUST, ALEKSANDRA ŁUCZAK, AGNIESZKA KOZERA}

\begin{abstract}
:
The purpose of this paper was to assess the conditional dependence structure in the precious metals futures market in the period spanning from the beginning of 2000 to mid 2018. These time frames correspond to large fluctuations of quoted contract prices during the financial crisis. The dynamic Kendall's tau coefficients and the dynamic tail dependence coefficients were used to assess the strength and dynamics of the nexus between rates of return on quoted prices of precious metals futures contracts. The coefficients were determined using the copula-based multivariate GARCH models, whereas the daily changes in the conditional dependence structure (changes in market state) were identified with the fuzzy c-means clustering method. In the study period, the conditional dependence structure in the precious metals futures market changed over time, as confirmed by the three identified market states. Of the contracts considered, gold and silver futures contracts demonstrated the strongest interrelationship and a relatively high likelihood of extreme events being transferred between them.
\end{abstract}

\section{Keywords:}

precious metals, copula-GARCH, dynamic dependencies, Kendall's tau coefficient, tail dependence, market states, fuzzy clustering method

JEL Classification: C58, C32, Q02

\section{Authors:}

MAŁGORZATA JUST, Poznań University of Life Sciences, Faculty of Economics and Social Sciences, Poland, Email: malgorzata.just@up.poznan.pl

ALEKSANDRA ŁUCZAK, Poznań University of Life Sciences, Faculty of Economics and Social Sciences, Poland, Email: aleksandra.luczak@up.poznan.pl

AGNIESZKA KOZERA, Poznań University of Life Sciences, Faculty of Economics and Social Sciences, Poland, Email: akozera@up.poznan.pl

\section{Citation:}

MAŁGORZATA JUST, ALEKSANDRA ŁUCZAK, AGNIESZKA KOZERA (2019). Conditional Dependence Structure in the Precious Metals Futures Market. International Journal of Economic Sciences, Vol. VIII(1), pp. 81-93., 10.20472/ES.2019.8.1.006 


\section{Introduction}

Over the centuries, precious metals (especially including gold and silver) increased their value and were often regarded as an attribute of power and wealth. Initially used mainly in coin and jewelry production, precious metals are now broadly used in industry, electronics, construction, medicine, dentistry or cosmetics sectors. As time went on, there was increased interest in precious metals as a potentially good investment during global market instability and crisis $^{1}$ (Adrangi, Chatrath, Raffiee, 2003; Levin, Wright, 2006; Beckmann, Czudaj, 2013).

Investing in the alternative instruments market, including in precious metals, is just as difficult as investing in stocks or other classic financial instruments. While gold is the most popular precious metal, investors can also opt for silver, platinum or palladium. In recent years, precious metals were believed to be a fairly secure investment opportunity, especially during the global market crisis. This is because precious metals are indestructible, independent, supranational and timeless; but most importantly they are resistant to changes in the stock market, especially as regards the physical metals segment. Indeed, as shown by a host of studies, precious metals (including gold and silver) may be used as a hedge against inflation both in the short and long term (Adrangi, Chatrath, Raffiee 2003; McCown, Zimmerman, 2007; Kasprzak-Czelej 2015, KhairAfham, Siong-Hook Law, Azman-Saini, 2017). Also, gold prices are believed to be less vulnerable to fluctuations in the national currency exchange rate (Capie, Mills, Wood 2005; Wang, Lee, 2011).

Currently, there are many opportunities for investment in precious metals, i.e. direct investments which mean a physical purchase of precious metals (e.g. gold bars, coins), futures contracts, stock markets, investment funds, ETFs and structured products (Mikita, Pełka, 2009). As noted by several authors, including Gierattowska (2016), precious metals are an important component of a well-balanced investment portfolio, especially if the investors want to establish a hedge against fluctuations and risks. The objective of such investments is to diversify the portfolio, having in mind that precious metals demonstrate a relatively low (positive or negative) correlation with most asset groups (Kasprzak-Czelej, 2013). A strong inflow of capital and the increased use of commodity markets, especially futures markets (as a way to diversify the investment portfolios) has been experienced since mid 2000s. The dynamic growth of commodity futures markets was strengthened by the development of e-commerce and the establishment of ETFs and passively managed index funds focused on commodities (Irwin, Sanders, 2012). However, Mayer, Rathgeber and Wanner (2017) indicate that commercial and long positions affect the level and volatility of metal prices much more than the activity of non-

\footnotetext{
1 In the period characterized by economic growth and improved financial performance of businesses, it is more beneficial - from the perspective of the investment portfolio - to reallocate the funds towards the stock market (as the demand increases, so do the stock prices) by moving them from the precious metals market (as the investment demand declines, so do the prices of precious metals) (Adrangi, Chatrath, Raffiee, 2003).
} 
commercial traders. They also claim that the level and volatility of metal prices are the driving force behind trading positions.

The literature presents a host of research on the existence and time stability of relationships between prices of precious metals (especially between gold and silver prices). While some studies indicate the existence of a long-term relationship between gold and silver prices, other suggest it is conditional or does not exist at all. However, the research on relationships between precious metal prices differs by data selection characteristics: spot prices, futures prices, data frequency; research period; changes in relationships over time being taken into account or not. Precious metals are believed to be a relatively homogenous group of interrelated commodities (Sensoy, 2013; Wanat, Papież, Śmiech, 2015). According to Wanat, Papież and Śmiech (2015), the global financial crisis did not affect the correlation structure of rates of return on precious metal prices. However, their study was based on spot prices of precious metals recorded from September 22, 1997 to February 13, 2014. It should be verified whether the above hypothesis is true for precious metal futures markets, considering their dynamic growth and other particularities.

The purpose of this paper is to assess the structure of conditional dependence between rates of return on quoted prices of precious metals futures contracts in the period spanning from the beginning of 2000 to mid 2018. The study relied on continuous series of daily closing prices of futures contracts on four precious metals (gold and silver from Commodity Exchange (COMEX), palladium and platinum from New York Mercantile Exchange (NYMEX)). The dynamic Kendall's tau coefficients and the dynamic tail dependence coefficients were used to examine the conditional dependence structure in the precious metals futures market. The coefficients were determined with the use of copula-DCC-GARCH models. The clustering method was used to identify the changes in the market's conditional dependence structure (changes in market states).

\section{Methodology}

To take into account the characteristics of the distribution of rates of return when modeling the dynamic relationships between the rates of return on quoted prices of precious metals futures contracts, the copula-DCC-GARCH model needs to be employed. The advantage of using the copula in multidimensional relationship modeling is that the multidimensional joint distribution (which defines the structure of relationships between the variables) is independent from their marginal distributions (Patton, 2007).

Using the conditional copula enables modeling joint distributions of an $n$-dimensional vector $\mathbf{y}_{t}=\left(y_{1, t}, \ldots, y_{n, t}\right) \quad(t=1, \ldots, T)$, conditional on a set of information $F_{t-1}$ available until and including $t-1$. The general conditional copula model is as follows (Patton, 2007):

$$
y_{1, t}\left|F_{t-1} \sim F_{1, t}\left(\cdot \mid F_{t-1}\right), \ldots, y_{n, t}\right| F_{t-1} \sim F_{n, t}\left(\cdot \mid F_{t-1}\right),
$$




$$
\begin{gathered}
\mathbf{y}_{t} \mid F_{t-1} \sim F_{t}\left(\cdot \mid F_{t-1}\right), \\
F_{t}\left(\mathbf{y}_{t} \mid F_{t-1}\right)=C_{t}\left(F_{1, t}\left(y_{1, t} \mid F_{t-1}\right), \ldots, F_{n, t}\left(y_{n, t} \mid F_{t-1}\right) \mid F_{t-1}\right),
\end{gathered}
$$

where: $C_{t}$ is the copula; $F_{t}$ and $F_{i, t}$ mean, respectively, the distribution function of joint distribution $\mathbf{y}_{t}$ and the distribution functions of marginal distributions $y_{i, t}$ at the moment $t$.

This paper assumes that the rates of return $r_{i, t}(i=1, \ldots, n, t=1, \ldots, T)$ on the prices of precious metal futures contracts are described with the ARMA-GARCH model (Doman, Doman, 2009):

$$
\begin{gathered}
r_{i, t}=\mu_{i, t}+y_{i, t}, \\
\mu_{i, t}=E\left(r_{i, t} F_{t-1}\right), \mu_{i, t}=\mu_{0 i}+\sum_{j=1}^{P_{i}} \varphi_{i j} r_{i, t-j}+\sum_{j=1}^{Q_{i}} \theta_{i j} y_{i, t-j}, \\
y_{i, t}=\sqrt{h_{i, t}} \varepsilon_{i, t}, \\
h_{i, t}=\operatorname{Var}\left(r_{i, t} \mid F_{t-1}\right), h_{i, t}=\omega_{i}+\sum_{j=1}^{p_{i}} \alpha_{i j} y_{i, t-j}^{2}+\sum_{j=1}^{q_{i}} \beta_{i j} h_{i, t-j},
\end{gathered}
$$

with $\varepsilon_{i, t} \sim i i d(0,1)$. The copula-DCC-GARCH model assumes that the joint conditional distribution of the $n$-dimensional vector $\varepsilon_{t}$ is modeled using a conditional copula with conditional correlations $\mathbf{R}_{t}$.

In turn, the conditional correlation matrix is obtained from the Dynamic Conditional Correlation (DCC) model (Engle, 2002):

$$
\begin{gathered}
\mathbf{H}_{t}=\mathbf{D}_{t} \mathbf{R}_{t} \mathbf{D}_{t}, \\
\mathbf{D}_{t}=\operatorname{diag}\left(\sqrt{h_{1, t}}, \ldots, \sqrt{h_{n, t}}\right), \\
\mathbf{R}_{t}=\left(\operatorname{diag}\left(\mathbf{Q}_{t}\right)\right)^{-1 / 2} \mathbf{Q}_{t}\left(\operatorname{diag}\left(\mathbf{Q}_{t}\right)\right)^{-1 / 2}, \\
\mathbf{Q}_{t}=\left(1-\sum_{k=1}^{K} a_{k}-\sum_{l=1}^{L} b_{l}\right) \overline{\mathbf{Q}}+\sum_{k=1}^{K} a_{k} \mathbf{u}_{t-k} \mathbf{u}_{t-k}^{\prime}+\sum_{l=1}^{L} b_{l} \mathbf{Q}_{t-l},
\end{gathered}
$$

where the conditional variance $h_{i, t}$ is modeled with a $\operatorname{GARCH}(p, q)$ model expressed as formula (7); $\overline{\mathbf{Q}}$ is the unconditional covariance matrix of variables $\mathbf{u}_{t}$, with $u_{i, t}=y_{i, t} / \sqrt{h_{i, t}}$; parameters $a_{k}, b_{l}$ meet the following conditions: $a_{k} \geq 0, b_{l} \geq 0$, $\sum_{k=1}^{K} a_{k}+\sum_{l=1}^{L} b_{l}<1$. In this study, two-dimensional copula-DCC-GARCH models were 
estimated using the maximum likelihood method, and the semi-parametric method of transformation was applied to the marginal innovations of the GARCH fitted models.

The Kendall's tau coefficient was used to assess the strength of the nexus between rates of return on quoted prices of precious metals futures contracts. Unlike the Pearson correlation coefficient (which may only be used for elliptical distributions), the tau coefficient is an adequate measure of dependence in the general case. If $\left(X_{1}, X_{2}\right)$ is a vector of a pair of random variables, and $\left(\tilde{X}_{1}, \tilde{X}_{2}\right)$ is that vector's independent copy, the Kendall's tau coefficient is expressed as follows (Doman, Doman, 2014):

$$
\tau\left(X_{1}, X_{2}\right)=P\left(\left(X_{1}-\tilde{X}_{1}\right)\left(X_{2}-\tilde{X}_{2}\right)>0\right)-P\left(\left(X_{1}-\tilde{X}_{1}\right)\left(X_{2}-\tilde{X}_{2}\right)<0\right) .
$$

In turn, if variables $X_{1}$ and $X_{2}$ are correlated with an elliptical copula, and the correlation coefficient is $\rho$, then the Kendall's tau coefficient is expressed as follows:

$$
\tau\left(X_{1}, X_{2}\right)=\frac{2}{\pi} \arcsin \rho .
$$

Two-dimensional distribution tail dependence coefficients (TDC) are used to determine the dependence between extreme values of random variables $X_{1}$ and $X_{2}$. If $F_{1}$ and $F_{2}$ are the distribution functions of variables $X_{1}$ and $X_{2}$ which are correlated with copula $C$, then the upper $\left(\lambda^{U}\right)$ and lower $\left(\lambda^{L}\right)$ tail dependence coefficients are expressed with the following formulas, respectively (Doman, Doman, 2014):

$$
\begin{aligned}
& \lambda^{U}=\lim _{\alpha \rightarrow 1^{-}} P\left(X_{2}>F_{2}^{-1}(\alpha) \mid X_{1}>F_{1}^{-1}(\alpha)\right)=\lim _{\alpha \rightarrow 0^{+}} \frac{\hat{C}(\alpha, \alpha)}{\alpha}, \\
& \lambda^{L}=\lim _{\alpha \rightarrow 0^{+}} P\left(X_{2} \leq F_{2}^{-1}(\alpha) \mid X_{1} \leq F_{1}^{-1}(\alpha)\right)=\lim _{\alpha \rightarrow 0^{+}} \frac{C(\alpha, \alpha)}{\alpha},
\end{aligned}
$$

with $\hat{C}\left(u_{1}, u_{2}\right)=u_{1}+u_{2}-1+C\left(1-u_{1}, 1-u_{2}\right)$. The upper (lower) tail dependence coefficient estimates the conditional probability of the occurrence of extremely high (low) values of a variable, provided that the other variable takes a very high (low) value. In the case of a Gaussian copula, $\lambda^{U}=\lambda^{L}=0$; in the case of a Student's $t$ copula with $v$ degrees of freedom and correlation coefficient $\rho>-1$ :

$$
\lambda^{U}=\lambda^{L}=2 t_{v+1}\left(-\sqrt{\frac{(v+1)(1-\rho)}{1+\rho}}\right) .
$$

The clustering method was proposed for the identification and assessment of the states of the precious metals market. While the number of various disjoint clustering methods is impressive, no single method exists which provides a universal approach to solving clustering problems in economic research. Therefore, in some cases, several clustering methods are used, and a comparison is then made between the results. However, the use 
of disjoint clustering methods involves some restrictions which result in a simplified solution where each unit is assigned to one cluster (state) only. In fact, many of these classifications are incorrect because each unit may demonstrate the characteristics of many states, and therefore the clustering structure may be fuzzy. One way to solve these problems are the clustering methods based on the fuzzy sets theory which enables assigning the units to more than one state.

Fuzzy clustering methods allow to assign the units to all classes with a defined degree of membership². Often, fuzzy clustering methods require the specification of the initial classification which may be determined based on the results of another clustering method (e.g. Jain, Moreau, 1987; Kamel, Selim, 1994). This paper proposes the initial classification to be determined with the k-means method (Hartigan, 1975; Hartigan, Wong, 1979), so that the results may be then used as input for the fuzzy $c$-means clustering algorithm (Bezdek, 1973; Pal, Bezdek, 1995). Fuzzy clustering provides a basis for identifying the states of the precious metals market together with the related degrees of membership, and to assess the transition time from one state to another.

\section{Data characteristics}

This study uses continuous series of daily closing prices of futures contracts on precious metals, as recorded from January 4, 2000 to June 29, 2018 (Stooq.pl). Focus was placed on COMEX gold and silver contracts and NYMEX palladium and platinum contracts. The continuous series were created by taking the most active contracts into consideration. All prices were synchronized by assigning the previous trading day price to missing pieces of data. Quoted contract prices are shown in Figure 1. In the study period, several subperiods of growth and decline in futures contracts on precious metals were identified. Some dramatic ups and downs in contract prices were experienced during the financial crisis.

Figure 1: Settlement prices of the futures contracts for precious metals* in the period 4.01.2000-29.06.2018

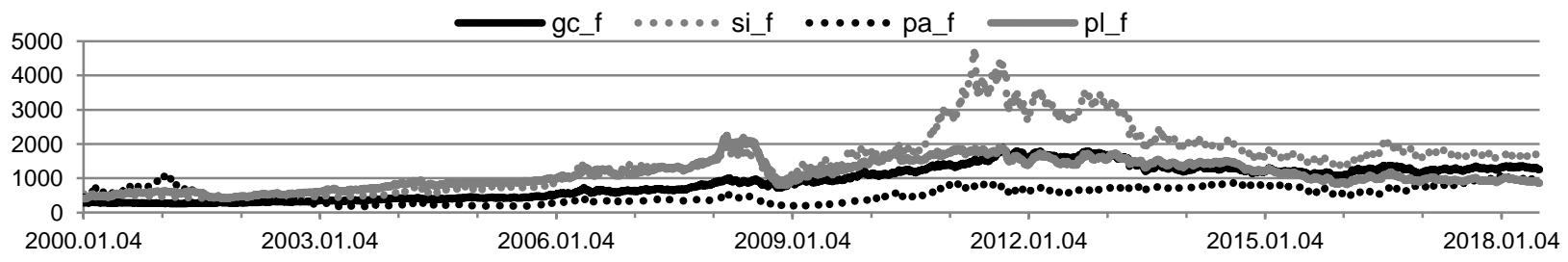

${ }^{*} g c \_f-g o l d$ futures contract (\$/ozt), si_f $f$ silver futures contract ( $\left.\phi / o z t\right), p a \_f-$ palladium futures contract (\$/ozt), pl_f-platinum futures contract (\$/ozt).

Source: Own adjustment based on data from (Stooq.pl).

\footnotetext{
2 The solution to the fuzzy clustering problem is the table of degrees of membership in particular clusters. Degrees of membership fall into the interval $\langle 0,1\rangle$, and the sum of all degrees of membership is equal to one. The degree of membership specifies the grade with which a unit belongs to the cluster concerned. The higher the degree, the more the characteristics of that cluster are applicable to the unit in question.
} 
The dependence between percentage logarithmic rates of return on prices of precious metal futures contracts was subject to analysis. The returns were calculated as $r_{t}=100 \ln \left(P_{t} / P_{t-1}\right)$, with $P_{t}$ denoting the contract's closing price at day $t$. The distributions of returns on all contracts under consideration were leptokurtic and demonstrated very weak or moderate negative asymmetry.

\section{$4 \quad$ Results of the study}

Because of the presence of autocorrelation in the series of rates of return on palladium and platinum futures contracts prices, the corresponding ARMA models were estimated (palladium - ARMA $(0,3)$, platinum - ARMA $(1,2)$ ). Afterwards, $\operatorname{GARCH}(1,1)$ models with a skewed Student's $t$ distribution were estimated for the series of rates of return on the prices of gold and silver futures contracts and for ARMA residuals estimated for the rates of return on palladium and platinum futures contracts. Because a strong ARCH effect was experienced even with a one-day lag, $\operatorname{GARCH}(1,1)$ models were estimated for the returns covered by this analysis with the following distributions: normal, skewed normal, Student's $t$, skewed Student's $t$, generalized error and skewed generalized error. The models were selected based on information criteria.

In the second stage of this study, two-dimensional copula-DCC-GARCH $(1,1)$ models with a Student's $t$ distribution were estimated for different pairs of futures contracts. Models with a Gaussian copula and with a Student's $t$ copula were considered ${ }^{3}$. The models were selected based on information criteria.

Because of the properties of rates of return, the strength of relationships between the rates of return on precious metal futures contracts in 2000-mid-2018 was measured with conditional correlation coefficients: the Kendall's dynamic tau coefficients (Figure 2).

The changes in the conditional dependence structure in the precious metals market were identified by clustering the Kendall's tau coefficients in time with the fuzzy c-means clustering method. An assumption was made that the typical conditional dependence structure pattern may be assigned to the market state concerned, and that large changes in the dependence structure correspond to the moments of transition between market states. The values of $K=6$ Kendall's tau coefficients for all pairs of returns on prices of futures contracts on four precious metals for $T=4692$ moments in time were arranged into a $K \times T$ matrix of data on the structure covered by this study. The values of characteristics were the basis for clustering. For that purpose, for 2 to 10 clusters the sequences of disjoint clustering were generated with use the $k$-means ${ }^{4}$ algorithm. These partitions were evaluated with the Krzanowski-Lai clustering quality index (1985). The Krzanowski-Lai index attained the first local maximum in the case of three clusters (the optimal partition). The initial clustering result obtained with $k$-means method was a basis for the fuzzy

${ }^{3}$ The calculations were performed in $\mathrm{R}$ (programming environment) with the rmgarch package developed by Ghalanos (2016).

${ }^{4}$ The calculations were performed in R with the clusterSim package developed by Walesiak and Dudek (2017). 
clustering based on $c$-means ${ }^{5}$. Three states of the precious metals market were identified (Figure 3). The fuzzy averages of Kendall's tau coefficients in specific market states are presented in Table 1.

Figure 2: Estimates of the dynamic Kendall's tau coefficients for dependencies between the returns of futures contracts for precious metals*
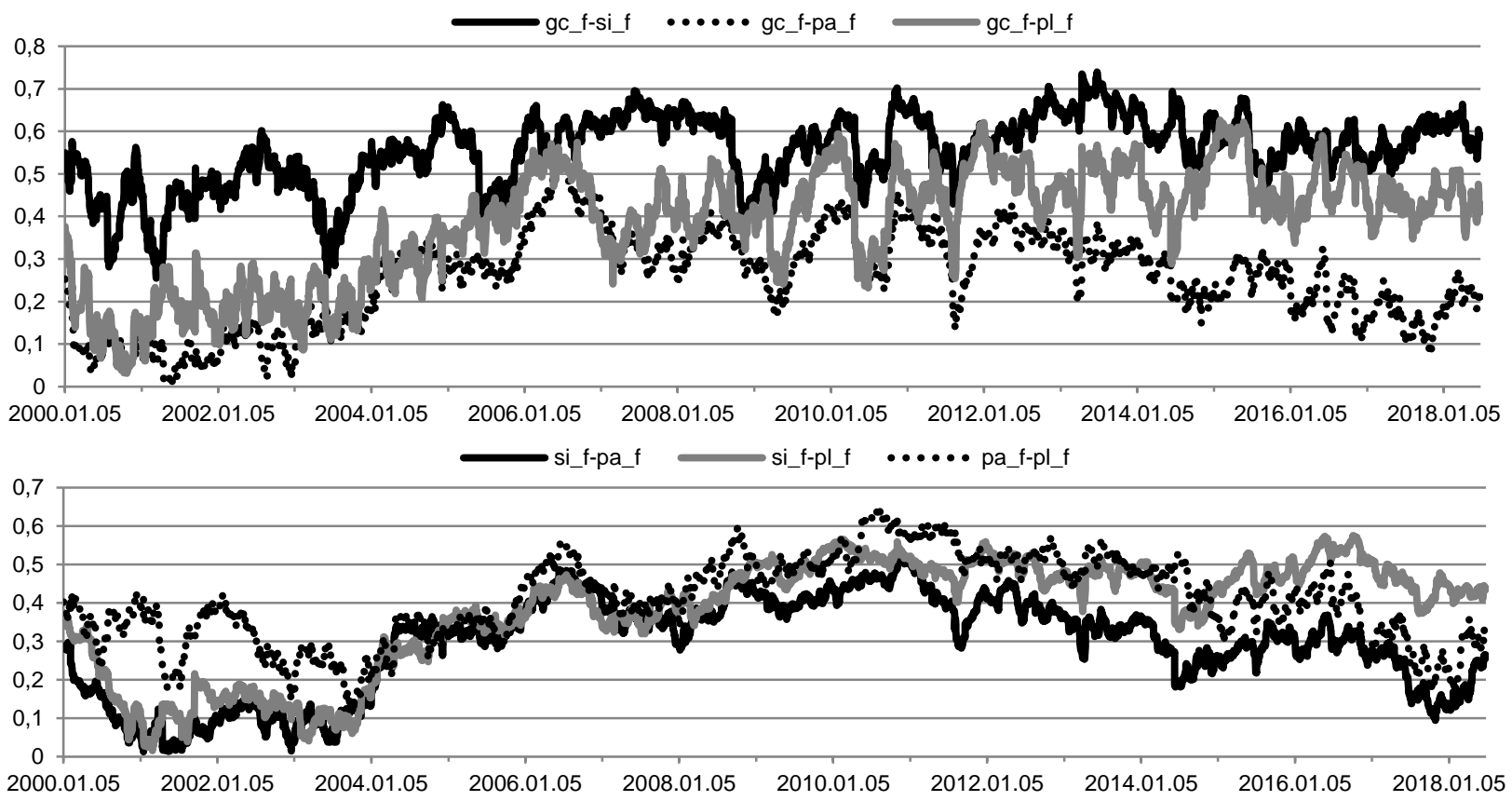

${ }^{*} g c \_f-g o l d$ futures contract; si_f $f-$ silver futures contract, pa_f $f-$ palladium futures contract, $p l \_f-$ platinum futures contract.

Source: Own adjustment based on data from (Stooq.pl).

Of the futures contracts analyzed, the strongest relationship existed between gold and silver contracts. The Kendall's tau coefficient values suggested a moderate or strong positive relationship between the rates of return on these contracts. Also, the relationship was found to be quite sustainable. In turn, the weakest relationship existed between gold and palladium contracts and between silver and palladium contracts. The strength of their relationships fluctuated considerably over the study period (varying from very weak to moderate and weak levels). A similar dynamic evolution of relationships was observed in the pairs of gold and platinum contracts and silver and platinum contracts. The strength of conditional correlation between the rates of return on these contracts was very weak or weak until 2004, strengthened considerably in the 2004 to mid 2006 period (goldplatinum: 0.57; silver-platinum: 0.47), and remained at a similar moderate level in subsequent years. In turn, conditional correlation between the rates of return on platinum and palladium contracts was moderate during most of the period considered (December 2005 to October 2016).

\footnotetext{
5 The calculations were performed in R with the fclust package developed by Giordani and Ferraro (2015).
} 
Figure 3: Temporal evolution of the precious metals futures market state

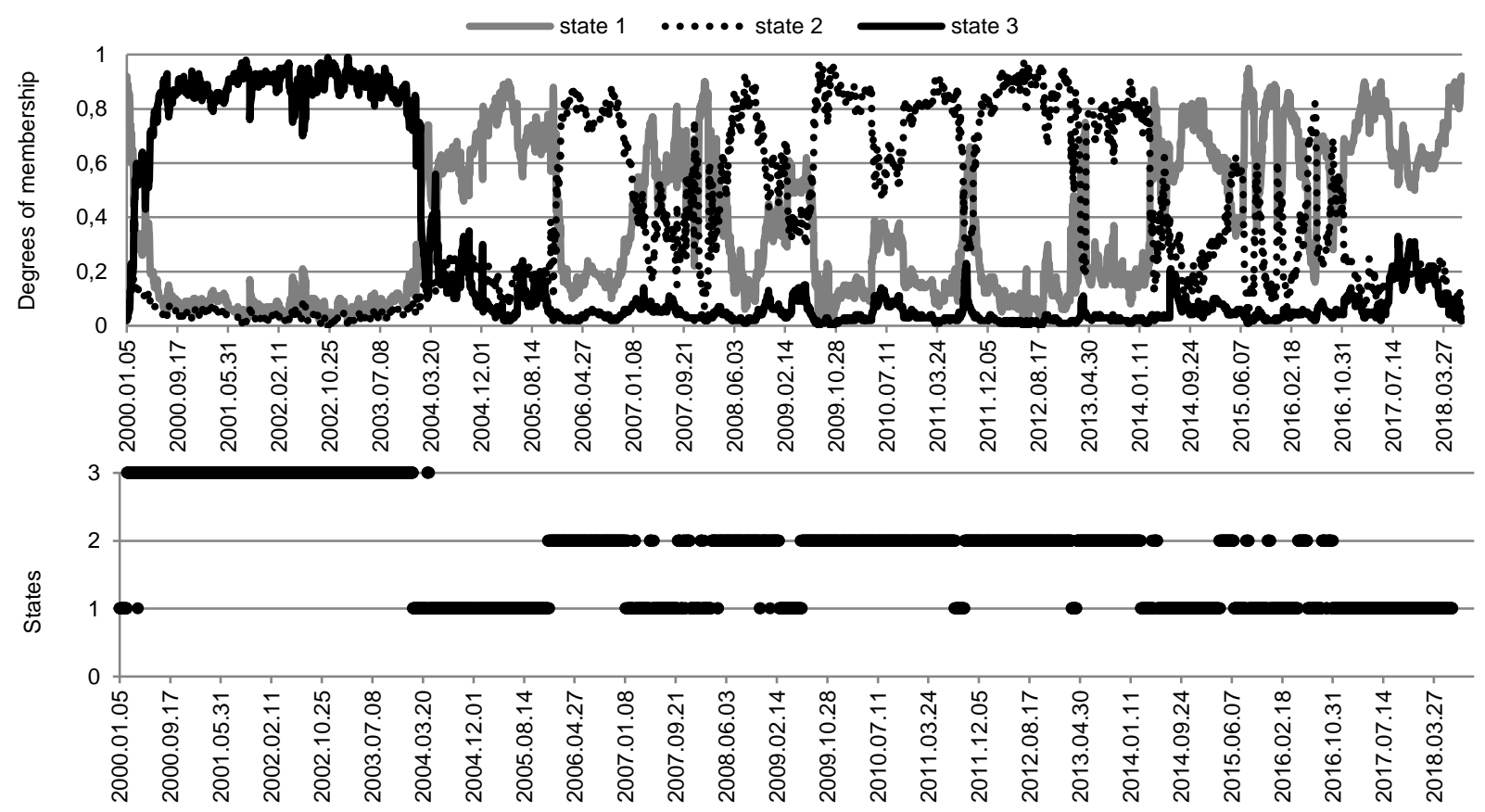

Source: Own adjustment based on data from (Stooq.pl).

Table 1: Fuzzy means of dynamic Kendall's tau coefficients for the precious metals futures* market states

\begin{tabular}{lcccccc}
\hline Specification & gc_f-si_f & gc_f-pa_f & gc_f-pl_f & si_f-pa_f & si_f-pl_f & pa_f-pl_f \\
\hline State 1 & 0.57 & 0.25 & 0.41 & 0.30 & 0.41 & 0.39 \\
State 2 & 0.59 & 0.33 & 0.46 & 0.37 & 0.46 & 0.48 \\
State 3 & 0.48 & 0.14 & 0.23 & 0.14 & 0.20 & 0.31 \\
\hline
\end{tabular}

${ }^{*} g c \_f-g o l d$ futures contract; si_f - silver futures contract, pa_f - palladium futures contract, $p l \_f-$ platinum futures contract.

Source: Own adjustment based on data from (Stooq.pl).

Similar conclusions can be drawn when analyzing Figure 3 and Table 1 data. A change in the conditional dependence structure in the market for precious metal futures contracts occurred on April 21, 2004. The market moved from the lowest (low) dependence level to a higher (moderate) dependence level. Wanat, Papież and Śmiech (2015) identified a considerable strengthening of relationships in the precious metals spot market which also took place in April 2004. Another shift in the conditional dependence structure occurred in mid-December 2005. The market reached the highest of all dependence levels considered (the moderate level) and maintained it until March 4, 2014 with some short interruptions (2007 - March 2008, March - June 2009, August - September 2011, March - April 2013). During most of the last sub-period (March 2014 - June 2018), the market remained at a lower (moderate) level of conditional correlation. This resulted from the weakening of the relationship between palladium contracts and other precious metals contracts. 
Figure 4: Estimates of the dynamic upper and lower tail dependence coefficients for the returns of futures contracts for precious metals*
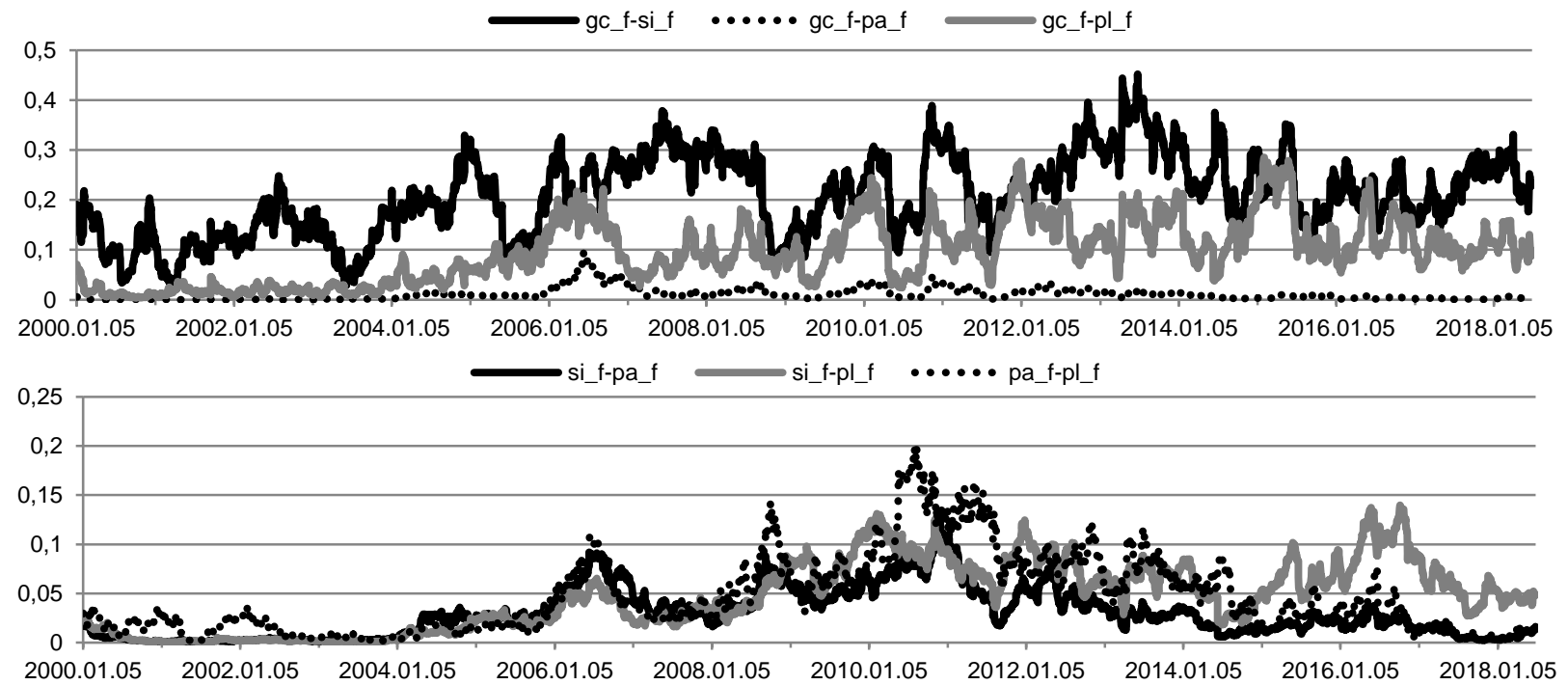

* $g c \_f-g o l d$ futures contract; si_f $f$-silver futures contract, pa_ $f$ - palladium futures contract, $p l \_f-$ platinum futures contract.

Source: Own adjustment based on data from (Stooq.pl).

The conclusion from the analysis of the dynamic evolution of tail dependence in joint conditional distributions (Figure 4) is that the highest values of the tail dependence coefficient were recorded between the pairs of gold and silver contracts. The likelihood of extreme events being transferred between the markets for these contracts increased in late 2004 and fluctuated around 0.3 until the end of the study period. In turn, the lowest likelihood of spillover (not in excess of 0.09) was observed between the markets for gold and palladium contracts. From the beginning of 2000 to mid-2006, extreme events were unlikely to be transferred between any pair of contracts other than gold and silver contracts. An increase in the likelihood of spillover between these contract markets was experienced in mid-2006. The increased likelihood of extreme being transferred between the palladium contracts market and other metal markets occurred during financial turmoil; but in the case of other contract markets, it lasted until the end of the study period. Therefore, it may be concluded that while the financial crisis did not have a considerable impact on regular relationships between the rates of return on quoted prices of precious metal contracts, it could have affected the strengthening of dependence in the distribution tails of rates of return on some contract prices. Seemingly, the considerable strengthening of regular relationships in 2004, and subsequently in late 2005, could have been related to the dynamic development of the market of precious metals contracts (a considerable increase in trading volumes).

\section{Conclusion}

As shown by the results, the dependence structure in the precious metals market underwent some changes in the period from 2000 till June 2018. The fuzzy c-means 
clustering method was used to identify three typical patterns of the conditional dependence structure (the states of the futures market for precious metals). The market state with the lowest (low) level of conditional correlation was identified in the period from early 2000 to mid-April 2004. Another market state was characterized by a considerably higher (moderate) conditional correlation level and spanned from mid-April 2004 to midDecember 2005, and then from March 2014 to June 2018. The highest (moderate) dependence level in the precious metals market was recorded in the period from midDecember 2005 to early March 2014. Of the contracts analyzed, gold and silver contracts demonstrated the strongest (and quite durable) interrelationship and a relatively high likelihood of extreme events being transferred between the respective markets. The results suggest that while the financial crisis did not have a considerable impact on regular relationships between the rates of return on quoted prices of precious metal contracts, it could have affected the strengthening of dependence in the distribution tails of rates of return on some contract prices. The analysis of the conditional dependence structure between precious metal futures contracts could be useful for the investors.

\section{References}

ADRANGI, B.; CHATRATH, A. and RAFFIEE, K. (2003). Economic activity, inflation, and hedging: The case of gold and silver investments. The Journal of Wealth Management, No. 6, pp. 60-77. https://doi.org/10.3905/jwm.2003.320482

BECKMANN, J. and CZUDAJ, R. (2013). Gold as an Inflation Hedge in a Time-Varying Coefficient Framework. North American Journal of Economics and Finance, No. 24, pp. 208-222. https://doi.org/10.1016/j.najef.2012.10.007

BEZDEK, J.C. (1973). Fuzzy mathematics in pattern classification. New York: Cornell University, Ithaca.

CAPIE, F.; MILLS, T. and WOOD, G. (2005). Gold as a Hedge against the Dollar. International Financial Markets, Institutions and Money, No. 15, pp. 343-352. https://doi.org/10.1016/j.intfin.2004.07.002

DOMAN, M. and DOMAN, R. (2009). Modelowanie zmienności i ryzyka. Metody ekonometrii finansowej (Volatility and risk modelling. Methods of financial econometrics). Kraków: Oficyna.

DOMAN, M. and DOMAN, R. (2014). Dynamika zależności na globalnym rynku finansowym (Dynamics of dependencies on the global financial market). Warszawa: Difin.

ENGLE, R.F. (2002). Dynamic Conditional Correlation. A Simple Class of Multivariate GARCH Models. Journal of Business and Economic Statistics, Vol. 20, pp. 339-350. https://doi.org/10.1198/073500102288618487

GHALANOS, A. (2016). Multivariate GARCH Models Packages "rmgarch" version 1.3-0. (cran.rproject.org/web/packages/rmgarch/rmgarch.pdf).

GIERAŁTOWSKA, U. (2016). Bezpośrednie i pośrednie inwestycje w metale szlachetne (Direct and indirect investment in precious metals). Annales $\mathrm{H}$ - Oeconomia, Annales Universitatis Mariae CurieSkłodowska Lublin - Polonia, Vol. L, No. 4, pp. 126-137. https://doi.org/10.17951/h.2016.50.4.125

GIORDANI, P. and FERRARO, M.B. (2015). Package 'fclust': Fuzzy Clustering. R-package version 1.1.2. (cran.r-project.org/web/packages/fclust).

HARTIGAN, J.A. (1975). Clustering algorithms. New York: John Wiley. 
HARTIGAN, J.A. and WONG, M.A. (1979). A K-Means Clustering Algorithm. Journal of the Royal Statistical Society. Series C (Applied Statistics), Vol. 28, No. 1, pp. 100-108. https://doi.org/10.2307/2346830

IRWIN, S.H. and SANDERS, D.R. (2012). Financialization and Structural Change in Commodity Futures Markets. Journal of Agricultural and Applied Economics, Vol. 44, No. 3, pp. 371-396. https://doi.org/10.1017/S1074070800000481

JAIN, A.K. and MOREAU, J.V. (1987). Bootstrap technique in cluster analysis. Pattern Recognition, Vol. 20, No. 5, pp. 547-568. https://doi.org/10.1016/0031-3203(87)90081-1

KAMEL, M.S. and SELIM, S.Z. (1994). A relaxation approach to the fuzzy clustering problem. Fuzzy Sets and Systems, Vol. 61, No. 2, pp. 177-188. https://doi.org/10.1016/0165-0114(94)90232-1

KASPRZAK-CZELEJ, A. (2013). Możliwości dywersyfikacji ryzyka z wykorzystaniem inwestycji alternatywnych (Opportunity to risk reduction with the use of alternative investments). Zarządzanie $i$ Finanse, Vol. 11, No. 2, pp. 255-266.

KASPRZAK-CZELEJ, A. (2015). Inwestycje w złoto jako zabezpieczenie przed inflacją w Polsce (Gold inwestments as a hedge against inflation in Poland). Annales $\mathrm{H}$-Oeconomia, Annales Universitatis Maria Curie-Skłodowska, Lublin - Polonia, Vol. XLIX, pp. 206-214. https://doi.org/10.17951/h.2015.49.4.205

KHAIR-AFHAM, M.S.M.; SIONG-HOOK, LAW and AZMAN-SAINI, W.N.W. (2017). Is Gold Investment a Safe Haven or a Hedge for the Malaysian Inflation? International Journal of Business and Society, Vol. 18, No. 1, pp. 51-66. https://doi.org/10.33736/ijbs.489.2017

KRZANOWSKI, W.J. and LAI, Y.T. (1985). A criterion for determining the number of clusters in a data set. Biometrics, No. 44, pp. 23-34. https://doi.org/10.2307/2531893

LEVIN, E.R. and WRIGHT, R.E. (2006). Short-Run and Long-Run Determinants of the Price of Gold. World Gold Council, Research Study, No. 32.

MAYER, H.; RATHGEBER, A. and WANNER, M. (2017). Financialization of metal markets: Does futures trading influence spot prices and volatility? Resources Policy, Vol. 53, pp. 300-316. https://doi.org/10.1016/j.resourpol.2017.06.011

McCOWN, J.R. and ZIMMERMAN, J.R. (2007). Analysis of the investment potential and inflation hedging ability of precious metals. Meinders School of Business, Oklahoma City University. https://doi.org/10.2139/ssrn.1002966

MIKITA, M. and PEŁKA, W. (2009). Rynki inwestycji alternatywnych (Alternative investment markets). Warszawa: Poltext.

PAL, N.R. and BEZDEK J.C. (1995). On cluster validity for the fuzzy c-Means Model. IEEE Transaction Fuzzy Systems, Vol. 3, No. 3, pp. 370-379. https://doi.org/10.1109/91.413225

PATTON, A.J. (2007). Copula-Based Models for Financial Time Series. Working Paper. (http://public.econ.duke.edu/ ap172/Patton_copula_handbook_19nov07.pdf).

SENSOY, A. (2013). Dynamic Relationship between Precious Metals. Resources Policy, Vol. 38, pp. 504511. https://doi.org/10.1016/j.resourpol.2013.08.004

Stooq.pl.

WALESIAK, M. and DUDEK, A. (2017). ClusterSim. Searching for Optimal Clustering Procedure for a Data Set. R-package version 0.47-1. (cran.r-project.org/web/packages/clusterSim). 
WANAT, S., PAPIEŻ, M. and ŚMIECH, S. (2015). The Conditional Dependence Structure between Precious Metals: A Copula-GARCH Approach. Zeszyty Naukowe Uniwersytetu Ekonomicznego w Krakowie, No. 4 (940), pp. 19-33. https://doi.org/10.15678/ZNUEK.2015.0940.0402

WANG, K.M. and LEE, Y.M. (2011). The Yen For Gold. Resources Policy, No. 36, pp. 39-48. https://doi.org/10.1016/j.resourpol.2010.06.002 